\title{
An investigation into possible factors that may impact on the potential for inappropriate prescriptions of antibiotics: a survey of general dental practitioners' approach to treating adults with acute dental pain
}

\author{
Ian Kerr, ${ }^{* 1}$ Debbie Reed, ${ }^{2}$ Anne-Maria Brennan ${ }^{3}$ and Kenneth A. Eaton ${ }^{4,5}$
}

\section{Key points}

Investigates the factors that might influence the inappropriate use of antibiotics in the management of acute dental pain before the COVID-19 pandemic.
Involves an online questionnaire-based survey of UK-based GDPs.
The survey collected data relating to the likelihood of antibiotics being used in two clinica scenarios.

\begin{abstract}
Objective To investigate factors that might influence inappropriate prescriptions of antibiotics (ABS) by UK-based general dental practitioners (GDPs) in their management of acute dental pain in adults in primary dental care.
\end{abstract}

Methods A questionnaire was circulated via social media to UK-based GDPs. The questionnaire examined GDPs' likelihood of issuing an inappropriate AB in two hypothetical clinical scenarios.

Results A total of 205 questionnaires were completed, of which 198 were included for analysis. The resulting data were analysed to try and identify factors that correlated with an increased likelihood of an inappropriate $A B$ prescription being issued for each clinical scenario. The results suggested the following factors as being associated with a statistically greater chance of the survey respondent issuing an inappropriate AB prescription: no postgraduate qualification; received their primary dental qualification from a non-UK university; scheduled appointments of less than 20 minutes; and low confidence in their ability to provide adequate local anaesthesia for the patients in the clinical scenario.

Conclusions Four factors were shown to be associated with dentists' stated intention to prescribe ABs for acute dental pain, not in accordance with guidance. These results should guide further research to understand the significance of appropriate $A B$ prescribing on the quality of urgent dental care. While the total number of respondents was too low to enable the results to be generalised, it is hoped that the results may help guide future research. Further studies could focus on these factors to understand more about their impact on the urgent care of adult patients in pain. The impact of the restrictions caused by the response to COVID-19 needs to be considered.

\section{Introduction}

Providing urgent pain relief for patients suffering from often debilitating levels of acute pain can represent one of the hardest challenges in general dental practice. ${ }^{1}$ The patient can be anxious and in a highly emotional state. Urgent care

${ }^{1}$ General Dental Practitioner, Hawkhurst, Kent, UK; ${ }^{2} \mathrm{Head}$ of Digital and Lifelong Learning, University of Kent, UK; ${ }^{3}$ Lecturer in Professional Practice, Director of Graduate Studies, Centre for Professional Practice, University of Kent, UK; ${ }^{4}$ Honorary Professor, Centre for Professional Practice, Medway Campus, University of Kent, UK; ${ }^{5}$ Visiting

Professor, University College London, UK.

${ }^{*}$ Correspondence to: Ian Kerr

Email address: info@stonerock.co.uk

Refereed Paper.

Accepted 12 August 2020

https://doi.org/10.1038/s41415-021-3008-x appointments are often squeezed into already busy treatment schedules, which adds to the challenge of trying to diagnose the cause of the pain, identify the offending tooth and provide appropriate local measures to provide relief. Coupled with this is the recognised challenge of achieving adequate local anaesthesia in patients with severe pulpitis, with rates as low as $17 \%$ reported for success with an inferior alveolar nerve block. ${ }^{2}$ It is worth noting that general dental practitioners (GDPs) providing this treatment under an NHS contract receive a fee of $£ 21.60$. This fee applies if the dentist opts to prescribe a course of antibiotics (ABs) for the patient as an alternative to providing an operative solution. ${ }^{3}$ This is in contrast to private GDPs who can charge for the provision of urgent care related to acute dental pain, with the fee reflective of the time taken to deliver the service.

Clinical guidelines on the use of $\mathrm{ABs}$ in the management of acute dental pain are issued by authoritative bodies such as the Royal College of Surgeons Faculty of General Dental Practice UK (FGDP[UK]), Scottish Dental Clinical Effectiveness Programme, British National Formulary and European Society of Endodontology. These indicate that operative procedures aimed at removing the source of inflammation or infection should be the first line of treatment. ABs should be reserved for cases where there is evidence of systemic involvement such as fever and malaise or spreading dental infection., ${ }^{4,5}$

In the UK, the FGDP(UK)'s Standards in dentistry ${ }^{6}$ is accepted as authoritative guidance 
and their advice on the management of acute pain gives an easy-to-understand guide as to what is expected at an urgent dental appointment. Despite this guidance, one study of UK GDPs ${ }^{7}$ found that over $75 \%$ of the patients were prescribed antimicrobials inappropriately. A further study conducted 15 years later ${ }^{8}$ found that this figure had increased, with over $80 \%$ of $\mathrm{AB}$ prescriptions being issued when their use was not clinically indicated. As a result of antimicrobial resistance (AMR), bacterial infections are on the increase and the Department of Health's five-year AMR strategy states that a leading cause of AMR is the indiscriminate or inappropriate prescription of ABs. ${ }^{9}$ It has been estimated that 25,000 deaths a year in Europe can be attributed to AMR, with $25 \%$ of the bacteria that cause serious infections in humans already resistant to ABs. ${ }^{10}$ Since March 2020, the restrictions placed upon dentistry by the response to the COVID-19 pandemic have put pressure on GDPs to provide more prescriptions for $\mathrm{ABs}$ in the absence of a thorough clinical examination. While this was not an issue at the time of gathering the data, the possible impact of COVID-19 clearly needs consideration, which takes place in the discussion section of this paper. The aim of this study was to identify which, if any, factors are likely to promote inappropriate $A B$ prescriptions by GDPs when managing adult patients with acute dental pain. It is hoped that the study will make an important contribution to the efforts to reduce the development and spread of infections that do not respond to ABs.

\section{Methods}

The study took the form of a self-completion questionnaire-based survey. After validation by a peer group of ten GDPs, the questionnaire was distributed via social media. This represented a cost-effective method that overcame the problem of a lack of a nationwide database of purely private practices throughout the UK. The population sampled was GDPs employed in the UK, who engage professionally with social media via two closed groups on Facebook, the most popular medium of social media in the UK. ${ }^{11}$ Approximately 55\% of UK GDPs engage professionally with various social media platforms, ${ }^{12}$ so it was reasonable to believe that a social media-based survey would access a wide range of GDPs in the UK. The population sampled should be considered as being non-random and collected via a convenience sampling technique. Power calculations for both online groups indicated target figures of 348 for the Restorative Implant Practice Excellence (RIPE) group and 374 for the Dentists for Dentists (D4D) group. RIPE was chosen as it is a site aimed at GDPs wishing to improve every aspect of their dentistry and is a site that the author is reasonably well known on. D4D was chosen as it has a large membership of predominantly UK-based GDPs. The questionnaire was distributed via the survey engine Online Surveys (www. onlinesurveys.ac.uk) and was followed up with a repeat request every one to two weeks for the 12 weeks of the survey.

Ethics approval for the study was granted by the Research Ethics Advisory Group of the University of Kent's Centre for Professional Practice. Gatekeeper approval was granted by administrators of both websites. Respondents consented to their involvement in the study via a tick box at the start of the questionnaire. The questionnaire (http://stonerockdentalcare.com/ ian-kerr-msc-survey/) contained 18 questions split into three sections. The first section collected data specific to each respondent while the second section was concerned with how the respondent's practice handled patients calling in need of urgent dental care. The final section provided two clinical scenarios: one representing severe pulpitic pain from a lower molar and the other representing acute apical periodontitis in a lower molar. According to current research and advice from authoritative guidelines, ${ }^{13,14,15}$ neither clinical scenario would require an $\mathrm{AB}$ prescription. The answers to the questions in the third section were recorded with a fourpoint Likert scale to help gauge the respondent's responses. Statistical significance of each test category was assessed using chi-squared tests to see which, if any, of the following factors were associated with an increased likelihood of the issuing of an inappropriate prescription for ABs:

- Site of qualification (UK or non-UK)

- Year of qualification (pre- and post-2000)

- Availability of a triage sheet

- Contract under which the treatment is provided (NHS or private)

- Length of appointment provided

- Possession of a postgraduate qualification

- How the respondents rated their chance of achieving adequate local anaesthesia.

\section{The two clinical scenarios as they were presented in the questionnaire}

The first scenario related to a patient presenting with severe pulpitis while the second related to a patient with symptoms of acute apical periodontitis - neither clinical situation would require a course of $\mathrm{ABs}$.

The same three questions were asked for each scenario. They were:

1. How long an appointment would you allocate for the treatment?

2. How would you rate the chances of you prescribing a course of $\mathrm{ABs}$ to manage this case?

3. How would you rate your chances of achieving adequate local anaesthesia for the treatment?

\section{Clinical scenario one}

A fit and healthy 52-year-old male patient with no relevant medical history requests an emergency appointment, complaining of severe dental pain that is exacerbated significantly by drinking tea but eased slightly by swilling cold water around his mouth. The pain has developed over the past three days and kept him awake last night. He describes the pain as sharp and stabbing and can be spontaneous in nature; the pain spreads from his chin to his ear on the right side of his face. He cannot say which tooth is to blame but thinks it may be coming from a lower back one; biting does not make the pain worse. He has been taking co-codamol tablets left over from his back surgery last year and reports that these give him about 30 minutes' relief.

On examination, he is seen to have a large, untreated carious cavity in his lower right first molar. The gingival health appears good and the tooth is not mobile, and no swelling is noted on intraoral or extraoral examination. A periapical radiograph taken at the time of examination reveals an intact lamina dura around the apices of both roots of this tooth. The tooth is in function and appears to be in a restorable condition.

\section{Clinical scenario two}

A fit and healthy 43-year-old female patient calls reporting severe dental pain and requests urgent treatment. She reports that the pain has developed over the past 48 hours and describes it as a deep, throbbing pain that comes in waves. It is spontaneous in nature and is not made worse by hot or cold. The patient is certain that the lower first molar is to blame as it feels tender when she pushes against it with her finger and when she bites down hard against it. Anti-inflammatory medication provides some relief from the pain but is needed every couple of hours to keep it under control. Examination 
shows that the first molar has been restored with a full-coverage porcelain fused to metal crown, which appears clinically sound. The gingival health appears good and the tooth is not mobile, and no swelling is noted on intraoral or extraoral examination. A periapical radiograph reveals very slight widening of the periodontal membrane space around the distal root when compared to adjacent apices. The patient is distressed by the level of pain that she is in but does not appear outwardly unwell.

\section{Results}

In total, 205 respondents completed the survey. From this total, it was necessary to exclude seven respondents as they had indicated that they were not currently working as GDPs in the UK. The response rate calculation was complicated by the unknown number of GDPs who received the survey twice by being in both online groups. Allowing for this limitation, it was calculated that $28 \%$ (205 from 722 , the combined power calculations) completed the questionnaire and responded.

\section{Demographic data}

Of the remaining 198 respondents, $171(86 \%)$ qualified from a UK-based dental school and 25 (13\%) from overseas dental schools; two (1\%) respondents declined to indicate where they graduated from.

The year of qualification provided a wide spread of responses, ranging from 1974 to 2019 (Fig. 1). Of the 198 respondents included for analysis, 133 (67\%) qualified from 1999 onwards (Table 1).

Of the 198 respondents, $44 \%$ had a postgraduate qualification.

A total of 40 respondents (20\%) indicated that they receive none of their income from the NHS; that is, they worked in practices that were wholly private, whereas 17 respondents (8\%) indicated that they receive no private income; that is, they worked in practices that were wholly NHS. The remainder of the respondents $(141,72 \%)$ indicated that they worked in practices that received a mixture of NHS and private patients. A scripted triage sheet can be used to help reception staff identify the level of urgency of care required for a patient calling in acute pain. The majority of respondents $(151,76 \%)$ worked in a dental practice where a scripted triage sheet was not available to assist receptionists when taking calls from patients in urgent need of care. Of the 198 respondents, 133 (67\%) worked

\section{Fig. 1 Distribution of respondents by year of qualification}

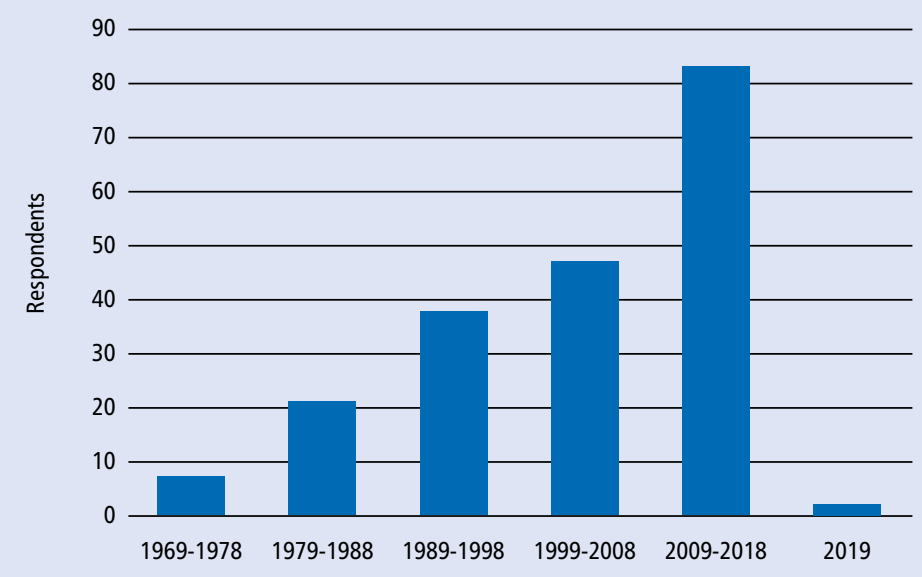

in a dental practice where an appointment was allocated for urgent care patients, with $119(60 \%)$ allowing under 30 minutes for this appointment (68 respondents [34\%] allocated less than 20 minutes).

\section{Data relating to the two clinical scenarios}

The data presented here relate to the responses to the same three questions asked after each clinical scenario:

1. How long an appointment would you to allocate for the treatment?

2. How would you rate the chances of you prescribing a course of $\mathrm{ABs}$ to manage this case?

3. How would you rate your chances of achieving adequate local anaesthesia for the treatment?

The answer to the first question was given in minutes via a drop-down selection while the answers to questions two and three were given a range of options: 'no likelihood, 'highly unlikely', 'highly likely' or 'certain'.

For the first scenario, seven (4\%) respondents indicated that their chance of issuing an $\mathrm{AB}$ prescription was 'highly likely' or 'certain'. For the second scenario, this number rose to 37 (18\%). Further analysis of the data revealed that the respondents who gave this rating for scenario one also gave the same rating for scenario two. A comparison was made between the 37 respondents who gave an answer of 'highly likely' or 'certain' for either scenario against those who responded with an answer of 'no likelihood' or 'highly unlikely' (Table 1).

Table 1 Analysis of results given by respondents indicating a high likelihood of antibiotic prescription compared to those indicating a low probability

\begin{tabular}{|c|c|c|c|}
\hline \multirow[b]{2}{*}{$\begin{array}{l}\text { Variables considered by the null } \\
\text { hypothesis }\end{array}$} & 37 respondents & 161 respondents & 198 respondents \\
\hline & $\begin{array}{l}\text { Highly likely/ } \\
\text { certain to } \\
\text { prescribe (\%) }\end{array}$ & $\begin{array}{l}\text { No likelihood/ } \\
\text { highly unlikely } \\
\text { to prescribe (\%) }\end{array}$ & All (\%) \\
\hline Total UK-qualified & $26(70 \%)$ & $142(89 \%)$ & $171(86 \%)$ \\
\hline Total non-UK-qualified & $11(30 \%)$ & $18(11 \%)$ & $25(13 \%)$ \\
\hline Total with additional qualification & $10(27 \%)$ & $77(48 \%)$ & $87(44 \%)$ \\
\hline Total without triage & $29(78 \%)$ & $122(76 \%)$ & $151(76 \%)$ \\
\hline Purely private & $6(16 \%)$ & $33(20 \%)$ & $40(20 \%)$ \\
\hline Purely NHS & $3(8 \%)$ & $13(8 \%)$ & $17(8 \%)$ \\
\hline Mixed & $28(78 \%)$ & $115(71 \%)$ & $141(72 \%)$ \\
\hline Local anaesthesia no chance/highly unlikely & $14(38 \%)$ & $11(7 \%)$ & $25(12 \%)$ \\
\hline Appointment less than 30 minutes & $25(67 \%)$ & $112(69 \%)$ & $137(69 \%)$ \\
\hline Pre-1999:post-2000 & $13: 24(35 \%: 65 \%)$ & $56: 105(34 \%: 66 \%)$ & $66: 133(33 \%: 67 \%)$ \\
\hline
\end{tabular}


The chi-squared tests were used with a Yates's correction, with the p value set at $<0.05$. Of the seven factors considered, four were found to be associated with a statistically significant increase in the likelihood of the use of an inappropriate $\mathrm{AB}$ prescription. These were:

1. Qualification from a non-UK university (Table 2)

2. Low or no confidence in achieving adequate local anaesthesia (Table 3)

3. Length of appointment provided but only when appointment times of less than 20 minutes were compared to all other times (appointment times of $<30$ minutes were not shown to be statistically more likely to be associated with an inappropriate $\mathrm{AB}$ prescription) (Table 4)

4. Lack of a postgraduate qualification (Table 5).

\section{Discussion}

The four variables found to be associated with a statistically significant increase in the likelihood of an inappropriate prescription of ABs among the respondents were: a lack of a secondary postgraduate qualification; having a primary dental qualification from a non-UK university; allowing appointments of less than 20 minutes; and expressing a low expectation of achieving adequate local anaesthesia. As stated in the results section, 205 dentists responded and completed the questionnaire. This number of responses fell below the number calculated by the power calculation, so any findings must be treated with caution and cannot be generalised to the population of GDPs within these groups.

The scenarios provided in the questionnaire presented clinical examples of acute severe pulpitis (scenario one) and acute apical periodontitis (scenario two). The teeth responsible for the pain were described as being in a restorable condition and the patients did not present with any possible medical complications. The signs and symptoms described in each scenario were representative of each clinical condition ${ }^{16}$ and reflect typical presentations of acute dental pain in a primary care setting. The percentage of respondents who indicated a rating of 'highly likely' or 'certain' for both or either scenario was lower than expected when compared to the evidence provided by previous clinical studies. One study ${ }^{17}$ which looked at patients attending an out-of-hours dental clinic reported that 50\% of attendees received $\mathrm{ABs}$ alone without local treatment where no diagnosis was made. A more recent survey ${ }^{18}$ which examined the approach to the management of acute pulpitis by GDPs found that $27 \%$ of respondents 'always or frequently prescribed antibiotics for pain in pulpitis. A cross-sectional study of GDPs in Wales ${ }^{19}$ found that $57 \%$ of acute dental pain patients received an $\mathrm{AB}$ prescription, and of these, $70 \%$ were issued without the provision of operative intervention.

Reasons for the differences in $\mathrm{AB}$ prescription rates for this survey are not clear but may relate to the style of population sampling in the current survey. By targeting online dental forums in a non-random manner, it is possible that the questionnaire attracted a sample of the GDP population that has a higher interest in and understanding of dentistry and is therefore less likely to prescribe $\mathrm{ABs}$ inappropriately than the general UK GDP population. It is also possible that the wording of the clinical scenarios provided a very clear and obvious diagnosis which does not always exist in true clinical scenarios; this may have made it easier for the respondents to avoid the use of inappropriate $\mathrm{AB}$ prescription, free from patient pressure and a more confusing clinical picture.

\section{UK-based vs non-UK-based qualification}

A total of 28 respondents (14\%) qualified from a non-UK university, with the distribution spread across 12 European Union (EU) and non-EU countries. The respondents in this survey who qualified from a non-UK university

\begin{tabular}{l|l|l|l}
\hline \multicolumn{3}{|l}{ Table 2 Location of primary dental qualification } \\
\hline Location & $\begin{array}{l}\text { Highly likely/ } \\
\text { certain }\end{array}$ & $\begin{array}{l}\text { Highly unlikely/no } \\
\text { likelihood }\end{array}$ & Totals \\
\hline UK university & 26 & 142 & 168 \\
\hline Non-UK university & 11 & 18 & 29 \\
\hline $\begin{array}{l}\text { Totals } \\
\begin{array}{l}\text { Key: } \\
*\end{array}=0.009276 \text { significant at } p<0.05 .\end{array}$ & 37 & 160 & $197^{*}$ \\
\hline
\end{tabular}

\begin{tabular}{l|l|l|l|}
\hline \multicolumn{3}{|l}{ Table 3 Confidence of achieving local anaesthesia } \\
\hline Confidence & $\begin{array}{l}\text { Highly likely/ } \\
\text { certain }\end{array}$ & $\begin{array}{l}\text { Highly unlikely/no } \\
\text { likelihood }\end{array}$ & Totals \\
\hline $\begin{array}{l}\text { Unlikely to achieve adequate } \\
\text { anaesthesia }\end{array}$ & 14 & 11 & $\mathbf{2 5}$ \\
\hline $\begin{array}{l}\text { Likely to achieve adequate } \\
\text { anaesthesia }\end{array}$ & 23 & 150 & 173 \\
\hline Totals & 37 & 161 & 198 \\
\hline $\begin{array}{l}\text { Note: } \\
p<0.000001 \text { significant at } p<0.05 .\end{array}$ & & & \\
\hline
\end{tabular}

\begin{tabular}{|c|c|c|c|}
\hline Appointment & $\begin{array}{l}\text { Highly likely/ } \\
\text { certain }\end{array}$ & $\begin{array}{l}\text { Highly unlikely/no } \\
\text { likelihood }\end{array}$ & Totals \\
\hline Below 20 minutes & 18 & 50 & 68 \\
\hline 20 minutes or over & 9 & 75 & 84 \\
\hline Totals & 27 & 125 & $152^{*}$ \\
\hline
\end{tabular}

\begin{tabular}{|l|l|l|l|}
\hline \multicolumn{5}{|l}{ Table 5 Possession of a postgraduate qualification } \\
\hline Postgraduate qualification & $\begin{array}{l}\text { Highly likely/ } \\
\text { certain }\end{array}$ & $\begin{array}{l}\text { Highly unlikely/no } \\
\text { likelihood }\end{array}$ & Totals \\
\hline With additional qualification & 10 & 77 & 87 \\
\hline Without additional qualification & 27 & 84 & 111 \\
\hline Totals & 37 & 161 & 198 \\
\hline $\begin{array}{l}\text { Note: } \\
p=0.034433 \text { significant at } p<0.05 .\end{array}$ & & & \\
\hline
\end{tabular}


were statistically more likely to provide an inappropriate $\mathrm{AB}$ prescription when compared to those who qualified in the UK.

The decision to include a question relating to the location of qualification was based on the recognised differences in attitudes towards $\mathrm{AB}$ prescriptions that exist across the globe. $\mathrm{A}$ systematic review ${ }^{20}$ reported a wide range of $A B$ prescription rates for pulpitis and acute apical periodontitis with $4.3 \%$ of Belgium dentists prescribing $\mathrm{ABs}$ for pulpitis, with this figure rising more than tenfold to $46 \%$ for dentists in Croatia. The same paper reported prescription rates in India for irreversible pulpitis and acute apical periodontitis to be as high as $72 \%$. The global discrepancies were echoed in a review study of $\mathrm{AB}$ consumption and $\mathrm{AMR}$ in Poland, ${ }^{21}$ which showed $A B$ prescription rates in Italy, Romania and Greece that were two to three times higher than those in the Netherlands, Estonia and Sweden. A 2009 survey of Spanish endodontists ${ }^{22}$ showed that $40 \%$ of respondents reported prescribing $\mathrm{ABs}$ for irreversible pulpitis, while a review conducted on the $A B$ awareness of final-year dental students in Italy ${ }^{23}$ indicated that almost $52 \%$ would prescribe $\mathrm{ABs}$ for acute apical periodontitis. A recent systematic review ${ }^{24}$ highlighted this point and investigated possible causes for such differences. When comparing high-income countries to low- and middle-income countries, the review identified possible causes for these differences as 'access', 'antibiotic beliefs', 'financial burden', 'patient influence' and 'treatment skills'. The results of this survey support the view that attitudes and use of ABs vary in different countries around the world, and suggest that the location of qualification has an impact on GDPs' inappropriate use of ABs in the UK.

\section{Low level of confidence in ability to} achieve adequate local anaesthesia

In the current survey, the correlation shown between those respondents who expressed a low level of confidence in their ability to achieve adequate local anaesthesia and those who expressed a high likelihood of issuing an $A B$ was seen to be statistically highly significant. This result is consistent with the findings of previous investigations that have looked at barriers to optimal care for patients suffering with acute dental pain ${ }^{25}$ and may reflect the well-documented difficulties associated with achieving adequate local anaesthesia in cases of acute dental pain. A systematic review ${ }^{26}$ investigated the success rates of local anaesthesia for lower molars with acute pulpitis and reported an average success rate of $51 \%$. A randomised controlled study ${ }^{27}$ showed similar success rates of $54 \%$ to $72 \%$ depending on the anaesthetic agent used.

\section{Length of appointment}

Previous studies which examined barriers to the provision of optimal care for patients suffering with acute dental pain have cited appointment length as a commonly reported problem. ${ }^{19,25}$ The results of this survey support this, but only when comparing the very shortest appointment times (recorded as less than 20 minutes) to all other times. No correlation was noted between $\mathrm{AB}$ use and the fee contract that treatment was provided under (NHS vs private). This is different to what might be expected, as out of the 132 respondents (60\%) who worked in mixed practices, 46 (34\%) indicated that shorter appointments were allocated for NHS patients. As part of the survey, respondents were quizzed on their use of a reception-based scripted triage sheet, which has been shown to be of importance in the management of acute dental pain ${ }^{28}$ and can help make appointment time more efficient. Unfortunately, the majority of respondents $(151,76 \%)$ worked in a dental practice where a scripted triage sheet was not available.

\section{Lack of a postgraduate qualification}

Of the 198 respondents, 87 (44\%) had an additional dental postgraduate qualification. When compared to the rest of the respondents, those with a postgraduate qualification were statistically less likely to provide an inappropriate $\mathrm{AB}$ prescription in either scenario. The number of years since qualifying did not seem to impact the use of ABs, with no statistically significant difference noted for those respondents who qualified pre2000 when compared to those who qualified after 2000. The impact of postgraduate qualification education on reduced $\mathrm{AB}$ use has been reported among $\mathrm{GPs}^{29}$ and has also been shown in dental literature. ${ }^{30}$ Despite a reported drop in the use of $\mathrm{ABs}$ in dentistry, ${ }^{31}$ the results from this survey would suggest that the potential for inappropriate prescriptions in the management of acute dental pain remains high and needs continued efforts to address it. Although this study was conducted before COVID-19, it seems entirely appropriate to discuss the findings with reference to the lockdown of March 2020 and the subsequent impact that this had on the provision of dental care in the UK. At a time when GDPs were restricted from seeing patients on a face-toface basis to provide normal routine care for almost three months, it can be assumed that many were put under significant pressure to provide $\mathrm{ABs}$ for acute dental pain, which would ideally have been treated via local intervention. Guidance was provided by authoritative bodies, ${ }^{32}$ which had the aim of helping GDPs to manage those patients with urgent dental need via a system of phone triage and remote prescribing, with urgent dental care centres set up for those patients with the greatest need. The primary care dental triage focused on the 'three As' of advice, analgesia and antimicrobials (where appropriate). The guidance on when $\mathrm{ABs}$ are appropriate for the management of patients in pain did not differ from previous recommendations from the pre-COVID-19 era. Despite this unchanging advice, it is feared that $\mathrm{AB}$ prescription rates may have gone up during the lockdown period (and the time to date where face-toface services are limited) due to increased demand from the public who were left without access to appropriate dental care. With this in mind, the need for continued vigilance over $\mathrm{AB}$ stewardship grows ever-more pressing as GDPs may mistakenly believe that ABs have a greater significance in acute pain management than they actually do.

\section{Conclusions}

Within the limitations of this investigation, the four factors identified as being associated with a statistically greater chance of an inappropriate $A B$ prescription being issued for the management of acute dental pain were: lack of a secondary postgraduate qualification; having a primary dental qualification from a non-UK university; allowing appointments of less than 20 minutes; and expressing a low expectation of achieving adequate local anaesthesia. Research into the management of patients with acute pain and the development of programmes aimed at reducing inappropriate $\mathrm{AB}$ use might consider targeting these areas in particular.

\section{Acknowledgements}

The authors would like to thank the GDPs who responded to the survey. The study was completed as part of an MSc in Professional Practice, awarded by the University of Kent.

Conflict of interest

The authors report no possible conflicts of interest with this paper. 
2019. Available at https://assets. publishing.service.gov. uk/government/uploads/system/uploads/attachment data/file/784894/UK_AMR 5 year_national_action plan.pdf (accessed July 2020)

10. Simonsen G. Antimicrobial resistance surveillance in Europe and beyond. Euro Surveill 2018; 23: 1800560.

11. Statista. Social media usage in the United Kingdom (UK) - statistics \& facts. 2021. Available at https:// www.statista.com/topics/3236/social-media-usage-inthe-uk/ (accessed April 2021).

12. Parmar N, Dong L, Eisingerich A. Connecting With Your Dentist on Facebook: Patients' and Dentists' Attitudes Towards Social Media Usage in Dentistry. J Med Internet Res 2018; DOI: 10.2196/10109.

\section{References}

1. Virdee S, Seymour D, Bhakta S. Effective anaesthesia of the acutely inflamed pulp: part 1. The acutely inflamed pulp. Br Dent J 2015; 219: 385-390

2. Nagendrababu V, Pulikkotil S, Veettil S Teerawattanapong N, Setzer F. Effect of Nonsteroidal Anti-inflammatory Drug as an Oral Premedication on the Anaesthetic Success of Inferior Alveolar Nerve Block in Treatment of Irreversible Pulpitis: A Systematic Review with Meta-analysis and Tria Sequential Analysis. J Endod 2018; DOI: 10.1016/j. joen.2018.02.017.

3. NHS.UK. What is included in each NHS denta band charge? [Internet]. 2018 [cited 6 May 2020]. Available from: https://www.nhs.uk/ common-health-questions/dental-health/ what-is-included-in-each-nhs-dental-band-charge/.

4. Cope A, Francis N, Wood F, Chestnutt I. Systemic antibiotics for symptomatic apical periodontitis and acute apical abscess in adults. Cochrane Database Syst Rev 2018; CD010136.

5. Agnihotry A, Thompson W, Fedorowicz Z, van Zuuren E, Sprakel J. Antibiotic use for irreversible pulpitis. Cochrane Database Syst Rev 2019: CD004969.pub5.

6. Faculty of General Dental Practice (UK). Standards in Dentistry. 2018. Available online at https://www. fgdp.org.uk/guidance-standards/standards-dentistry (accessed May 2020)

7. Dailey Y, Martin M. Are antibiotics being used appropriately for emergency dental treatment? Br Dent 2001: 191: 391-393.

8. Cope A, Francis N, Wood F, Chestnutt I. Antibiotic prescribing in UK general dental practice: a crosssectional study. Community Dent Oral Epidemiol 2015; 44: 145-153.

9. HM Government. Tackling antimicrobial resistance 2019-2024: The UK's five-year national action plan.
13. Fedorowicz Z, Keenan J, Farman A, Newton T. Antibiotic use for irreversible pulpitis. Cochrane Database Syst Rev 2005; DOI: 10.1002/14651858.CD004969.pub2.

14. Cope A, Francis N, Wood F, Chestnutt I. Systemic antibiotics for symptomatic apical periodontitis and acute apical abscess in adults. Cochrane Database Syst Rev 2018; DOI: 10.1002/14651858.CD010136.pub3.

15. Faculty of General Dental Practice (UK). Antimicrobial Prescribing in Dentistry. 2016. Available online at https://www.fgdp.org.uk/guidance-standards/ antimicrobial-prescribing-in-Dentistry (accessed May 2020).

16. Rechenberg D, Held U, Burgstaller J, Bosch G, Attin T. Pain levels and typical symptoms of acute endodontic infections: a prospective, observational study. BMC Oral Health 2016; 16: 61-68.

17. Tulip D, Palmer N. A retrospective investigation of the clinical management of patients attending an out of hours dental clinic in Merseyside under the new NHS dental contract. BrDent J 2008; 205: 659-664.

18. Gemmell A, Stone S, Edwards D. Investigating acute management of irreversible pulpitis: a survey of general dental practitioners in North East England. Br Dent $J$ 2020; 228: 521-526.

19. Cope A, Francis N, Wood F, Chestnutt I. Antibiotic prescribing in UK general dental practice: a crosssectional study. Community Dent Oral Epidemiol 2015; 44: 145-153.

20. Segura-Egea J, Martín-González J, Jiménez-Sánchez $M$ Crespo-Gallardo I, Saúco-Márquez J, Velasco-Ortega E. Worldwide pattern of antibiotic prescription in endodontic infections. Int Dent J 2017; 67: 197-205.

21. Wojkowska-Mach J, Godman B, Glassman A et al. Antibiotic consumption and antimicrobial resistance in Poland; findings and implications. Antimicrob Resist Infect Control 2018; 7: 136
22. Rodriguez-Núñez A, Cisneros-Cabello R, Velasco-Ortega E, Llamas-Carreras J, Tórres-Lagares D, Segura-Egea J. Antibiotic Use by Members of the Spanish Endodontic Society. J Endod 2009; 35: 1198-1203.

23. Salvadori M, Audino E, Venturi G, Garo M, Salgarello S. Antibiotic prescribing for endodontic infections: a survey of dental students in Italy. Int Endod J 2019; 52: 1388-1396.

24. Thompson W, Tonkin-Crine S, Pavitt S et al. Factors associated with antibiotic prescribing for adults with acute conditions: an umbrella review across primary care and a systematic review focusing on primary dental care. J Antimicrob Chemother 2019; 74: 2139-2152.

25. Newlands R, Duncan E, Prior M et al. Barriers and facilitators of evidence-based management of patients with bacterial infections among general dental practitioners: a theory-informed interview study. Implement Sci 2015; 11: 2-12.

26. Nagendrababu V, Pulikkotil S, Suresh A, Veettil S, Bhati $S$, Setzer F. Efficacy of local anaesthetic solutions on the success of inferior alveolar nerve block in patients with irreversible pulpitis: a systematic review and network meta-analysis of randomized clinical trials. Int Endod J 2019; 52: 779-789.

27. Allegretti C, Sampaio R, Horliana A, Armonia P, Roch $R$, Tortamano I. Anaesthetic Efficacy in Irreversible Pulpitis: A Randomized Clinical Trial. Braz Dent J 2016; 27: 381-386.

28. Kirton J, Thompson W, Pearce M, Brown J. Ability of the wider dental team to triage patients with acute conditions: a qualitative study. Br Dent J 2020; 228: 103-107.

29. Public Health England. Behaviour change and antibiotic prescribing in healthcare settings: literature review and behavioural analysis. 2015. Available at https:// assets.publishing.service.gov.uk/government/uploads/ system/uploads/attachment_data/file/774129/ Behaviour_Change_for_Antibiotic_Prescribing_FINAL.pdf (accessed May 2020).

30. Agnihotry A, Gill K, Stevenson III R G et al. Irreversible Pulpitis - A Source of Antibiotic Over-Prescription? Braz Dent J 2019; 30: 374-379.

31. Bunce J, Hellyer P. Antibiotic resistance and antibiotic prescribing by dentists in England 2007-2016. Br Dent 2018; 225: 81-84.

32. Scottish Dental Clinical Effectiveness Programme. Management of Acute Dental Problems During COVID-19 Pandemic. 2020. Available online at https:// www.sdcep.org.uk/published-guidance/acute-dentalproblems-covid-19/ (accessed July 2020) 